\title{
A clash of human resource management cultures: a micro-state case study
}

\section{Godfrey Baldacchino}

\begin{abstract}
When resorting to Greek divine mythology to purchase original insights on management styles, Handy (1991) identifies Apollo and Dionysius as representative of two ideal types which can be developed and fine-tuned to highlight one relatively underexplored area of inter-cultural human resource management. This concerns the cultural interface between alien, imported management styles and local, home-grown practices in the context of small and island states. This paper argues that indigenous behaviour patterns in the unfolding of labour-management relations cannot be discounted. Indeed, these home-bred practices will both place imported 'textbook' management strategies in sharp relief as well as debilitate their purposed efficacy. Such a proposition suggests that this is one expression of how globalization will necessarily find itself textured and infected by indigenous cultural material, even that forthcoming from possibly the least expected quarter: that of micro, insular jurisdictions. Case-study material exploring and illustrating this cultural clash is drawn from seminal, empirical fieldwork carried out in the Indian Ocean island state Republic of the Seychelles.
\end{abstract}

Keywords Human resource management, cultural collision, imported management strategies, indigenous behaviour, Seychelles

\section{Introduction}

Within the recent, rapid increase in interest in professional management formation, there has been a tendency to root such a development in the 'how-to', technical side. The growth of a strategic management philosophy - with uncritical rote learning of lists, methods and formulae - has meant increasing attention and resources being devoted to the training, rather than the education, of upcoming management cadres (Olsen et al., 1991; 219-20). There is also rife ample 'guru hype', with various courses, textbooks and consultants arguing that there exists a single, standard 'best practice' in management, irrespective of context (e.g. Kotas, 1980; Woods, 1982). One result of such a socialization process is that, as management becomes more global in orientation, it instinctively assumes that it is expected to transplant its own, obviously culturally superior, baggage into different cultural contexts. Such self-righteousness is more likely when firms take pride in their corporate identity and seek, naturally and stubbornly, to make this cascade down to all their rank and file (e.g. Ferner and Edwards, 1995: 237).

Intercultural management, therefore, constitutes a behavioural flashpoint, especially in such industries as tourism and hospitality. Managerial staff need to become first of all aware of, and subsequently adaptable to, the multicultural facets of their 'product'. Cultural imprinting will prove increasingly unacceptable, even distasteful, to many discerning customers of differing nationality, race or creed. Furthermore, such ethnocentrism will also run into serious problems on the labour-management front. 
Human resource management is being advised to become more behaviourally attuned; but the sensitivity is just as strongly required in the sphere of labour-management, apart from host-guest, relations.

\section{The social island setting}

The milieu selected for operationalizing the above argument is that of a small and island state. The choice is, to say the least, unusual; but this presents the best empirical expression of a small-scale setting. The actors therein are also more prone to acknowledge and exhibit a 'street wisdom' on such affairs, unlike actors in other (including small-scale) settings elsewhere.

Furthermore, the micro-state setting bears a relevance much wider than the world's three dozen or so small, insular, sovereign territories. We are resorting to an understanding of insularity beyond the strictly physical sense, illustrating a phenomenon of community isolation (King, 1993: 15-19). Hence, not only the sea but an isthmus, a desert, a heavy snowfall, a military siege operation, a mountain range. . all can act to engender a 'social island' condition (Pitt, 1980). Apart from these circumscribed sites, there are enterprise-specific 'total institutions' which also act to foster conditions of isolation and panopticism: mental asylums (Goffman, 1961); prisons (Foucault, 1977); ships (Tunstall, 1969); coal mining communities (Dennis et $a l ., 1956)$; company towns (Rushen, 1995); hotels (Shamir, 1981). The circumstance is also typical of many micro-enterprises, with their characteristic face-to-face, paternalist relationship between employers and workers (e.g. Harrod, 1988: 196-203).

\section{Micro-state research}

It is only in the last few decades that a serious attempt has been made to explore critically the idiosyncrasies of small and island states. No doubt, this area of research was by definition non-existent until such a category of independent, sovereign units started taking their place on the world's geo-political map, albeit somewhat late in the epoch of decolonization. Such states have themselves commissioned internal and external studies which, within the single case study or comparative framework, investigate specific developmental issues in a small, island milieu - particularly public administration (e.g. Baker, 1992), economic growth and development (Dommen and Hein, 1985; McKee and Tisdell, 1990), educational provision (Bray and Packer, 1993) and tourism (Briguglio et al., 1996a, 1996b; Lockhart and Drakakis-Smith, 1996). The fascination of the insular world and its fair share of associated glamour, beauty and mystique have no doubt contributed to such locations becoming academic curios and excellent excuses for the cultural tourism on which many of these locations thrive. Paradoxically, it is the global impact of tourism and long-haul airline travel which has made it at last physically feasible to place many of these erstwhile forlorn destinations on the itineraries of academics as well as pleasure seekers. Hence, hitherto impractical comparative, international and regional, research in this field lies now within the reach of project budgets and time frames.

Furthermore, the latest (post-modern?) trend in the analytical social sciences is precisely to depart from grand, maximizing explanations and to venture into a more indepth, interdisciplinary and holistic appreciation of the specific, in a style traditionally associated with anthropology (Laclau, 1990: 190; Sztompka, 1990: 55). That this social science was actually ushered in and popularized thanks to the observation of islander behaviour (Malinowski, 1922; Firth, 1936; Mead, 1949) suggests an uncanny return to 
a consideration of these physically discrete loci of civilization. This time, however, they are not being visited by virtue of presenting themselves as prototype and convenient, social laboratory settings (e.g. Cammish, 1980: 55; Bayliss-Smith et al., 1988: 284). Rather, the current concern is to consider these as territories harbouring a peculiar compendium of features which usher in a tendency for a particular cluster of behaviour patterns, or 'ecology' (Commonwealth Secretariat, 1986: 6).

\section{Proposal}

This article proposes to explore one facet of this small and island state condition: that relating to the value collision between local and foreign human resource management styles. That such styles should and can be identified at all is itself part of the condition of such an encounter which acts to sharpen and highlight these tendencies, even at the cost of stereotyping them and locating them on diametrically opposed poles.

Such intercultural friction is one expression of the idiosyncratic interplay between openness and closure in small and island states (Villamil, 1977). On the one hand, there is a ready disposition to welcome, actively or invariably, a diverse range of alien imports: consumer goods, expatriate consultants, educational exams and textbooks, even foreign languages and religions - a profound sense of cultural cloning, dependency inclination or a macro-state emulation syndrome (Harrigan, 1974; Khan, 1976: 49). On the other hand, the long, intimate and stifling nature of foreign penetration - coupled with the equally burdensome tourist presence - provides an endogenous boost for the rationalization and affirmation of the 'insular identity' - the maintenance and reproduction, at times even the invention, of the local cultural compendium.

Comparative and preliminary fieldwork undertaken in Barbados and Malta, two small, island states in the Caribbean and the Mediterranean respectively, provides substantive clues to this small island syndrome. The research results, published elsewhere (e.g. Baldacchino, 1994, 1996, 1997), intimate a rich and assorted behavioural universe where there is unfolded a unique reciprocation of totality and monopoly at the level of the individual, along with the pervasiveness of a transparent society with a low threshold of privacy. Role diffusion (pressure towards generalist functions) is juxtaposed with role multiplicity (the wearing of a variety of hats in simultaneity and/or succession) as well as with role specialization (the achievement and holding on to expert status). These capacities in turn facilitate, and are facilitated by, the criss-crossing of obligations and functional, person-specific contacts and dealings. Such exchanges are themselves embedded in the complex and clannish social relations of obligation, sympathy and antipathy. Conditions of work thus appear to harbour a greater possibility and opportunity for job enlargement, for 'professional' indulgence and for authoritarian stature. Yet all this is circumscribed within a generally boom and bust, externally oriented and dependent environment which makes diversification and polyvalence a viable survival strategy at home. The only feasible exit option is emigration and voluntary exile.

In such an environment, human resource management practices and labourmanagement relations generally are more liable to person- (rather than office-) specific deals. Managers and managed, men and women, deploy an impressive repertoire of customized, accommodational strategies to lobby and influence the extant power relationship and its typically faceless, à la carte, orientation. 


\section{People versus roles}

In Handy's (1991) juxtaposition of these styles with the deities of classical Greek myth, one is confronted with a local Dionysius culture where the person is all important: the cultural equipment and circumstances permit, expect and cultivate a contouring of jobs around discrete individuals. Handy (1993: 189) claims that such an organizational characteristic is unusual and will not be found to be pervading many organizations. Yet, in the small and island state context, people are likely to matter more and the widespread opportunities for monument building and achieving monopoly status are unparalleled (e.g. Bray and Fergus, 1986; Farrugia, 1991). Organizations may succumb to becoming, or else be construed as, devices to push forward and consolidate personal ambitions. The orientation is existentialist and the structural minimalism renders the organizational inhabitants like stars in a cluster. Where there are sites of power inequality in this cluster, then such gravitational relationships will also be essentially conscribed and cast around specific persons. These strategies of behaviour and of power preservation and maximization within the labour process well up from the lower levels of an organizational hierarchy and percolate upwards.

The higher they permeate, however, the more likely they are to meet with an alternative, and more prescriptive, top-down human resource strategy. Handy refers to this as the Apollo culture: a culture of roles, of a functional division of labour, of an organizational ethos premised on a legal-rational, Weberian bureaucratic model. Here, a Procrustean structure comes to the fore, driven by its inherently mechanistic and faceless logic.

What is the nature of such a cultural collision in the small, island-state setting as it impinges upon human resource management? How and to what extent do employees manage to transform anonymous, blanket procedures and regulations into personal opportunities? To what degree is management party to this practice or otherwise oblivious of these 'making-out' power games (after Burawoy, 1985) at work?

\section{Seychelles}

The location to ground the answer to such a question is one about which very little indeed has been written in academic circles. Indeed, the setting has been heavily themed by the tourism industry as the image of an unspoilt Eden. Writing about the Seychelles appears justifiable only to the discerning tourist.

The Seychelles is an archipelago republic occupying the western part of the Indian Ocean. The main granitic island of Mahé has a total land area of 154 sq. km, with some 114 other named islands, mainly coralline, occupying a further land area of $291 \mathrm{sq} . \mathrm{km}$. The bulk of the population of 75,000 live on the main island. Other than fleeting references by early Phoenician, Arab and Indonesian navigators, the islands were 'discovered' by Vasco da Gama in 1502. The first active settlement was by the French but, after the Treaty of Paris of 1814, the administration of the islands was passed over to Britain. The Seychelles became a Crown Colony in 1903, separate from Mauritius from where it had until then been governed. Some political reforms went some way towards establishing a modicum of self-government, and a coalition by the two main political parties steered the Seychelles to political independence in 1976. After oneparty rule for fifteen years, the country has committed itself to political pluralism as from 1993. The economy has these last years been experiencing a mini-boom, thanks to 
solid performance in tourism, construction and fish (particularly tuna) processing. The latter is possible thanks to the island's jurisdiction over one of the world's largest exclusive economic zones of 1.3 million sq. $\mathrm{km}$.

\section{The human resource endowment}

The human resource factor is acknowledged as a severe bottleneck in the context of economic development in the Seychelles. This is in part due to a tight labour market and a legacy of over-dependence on state provision for employment which was not necessarily market sensitive and which includes over-manning (Republic of Seychelles, 1996: 17). There has also been a recent policy shift in favour of privatization of state assets, liberalization and a diversification into a more mixed economy with a strong contribution by local and foreign private entrepreneurs. These measures have strained the local human resource pool still further. Such constraints exist apart from the minimum requirements or critical mass exigencies of any independent country: 'A total labour force of just less than 25,000 in formal employment does not offer the critical mass necessary to sustain many trades and professions and effectively prevents the development of ancillary services or expertise by nationals' (Republic of Seychelles, 1996: iv). There are limitations, associated further with the small, island condition. As this same recent official document attests, 'The limited domestic manpower base, arising from the small size of the country, imposes its own constraints' (Republic of Seychelles, 1996: iv).

Similar conclusions are reached by Gabbay and Ghosh (1992) and Aminuzzaman (1992). In detail, such problems include chronic labour shortages, especially with respect to skilled and technical labour, compounded by a brain and skill drain of local, skilled personnel. The latter discover to their dismay that the range of skills required locally is simply too narrow to sustain and challenge their specialism; opportunities for higher remuneration or job enrichment are not available in their home country: 'Higher labour mobility may be inevitable in a very small economy where macro-level enterprises limit one's opportunities to progress and develop' (Republic of Seychelles, 1996: 18). Furthermore, there is a tendency to overload the talented, given their inability to escape from a plethora of low-level routine, administrative and consultancy tasks, when and if they decide not to leave (Pillay and Murugiah, 1991: 73).

\section{Expatriates}

As a result of these constraints, the Seychelles Government has been obliged to pursue a policy of expatriate recruitment. Over 1,500 expatriates are engaged at the time of writing (May 1996) in a variety of professional, managerial and technical functions. ${ }^{1}$ Steps have been taken to identify consultancy capacity among the local Seychellois and to activate a vigorous manpower development and training programme, particularly at middle-management level, following a national training-needs analysis exercise. Yet the expatriate phenomenon appears to have established itself as a subtle yet powerful political lobby which acts as a proper self-reproducing recruitment agency, particularly for hopeful, short-term, guest workers from European labour markets currently experiencing high rates of unemployment. In spite of a widespread understanding of the need to promote localization, 'dramatic reductions in the number of expatriates cannot be expected in the short-term' (Republic of Seychelles, 1990: 89). 


\section{Cultural clash potential}

The expatriate condition in the Seychelles exacerbates the cultural clash of management styles. It is already fairly common to find senior local management practitioners from small island states who have studied the principles of the human resource function (induction, motivation/control, development, appraisal) in foreign educational institutions or from foreign textbooks and management manuals. Even in the case of those management personnel who have been exposed to human resource management thinking from 'local' sources, these are bound to have done so via expatriate tutors or local tutors who have nevertheless gone for training abroad or similarly obtained their inspiration from foreign canons of management practice, typically of British or American origin. While such conditions hold in the Seychelles, there is furthermore a clear spread of, particularly, Indian, South African and British 'expat' consultants who occupy authoritative positions in public, parastatal or private organizations.

The foreign-local rift is thus sharpened considerably in such instances since the dynamic relationship which invariable charges the labour-management dynamic has a readily discernible, physical, linguistic and national (apart from cultural) imprint. This carries along with it some other obvious differences in the conditions of work. Indeed, the pre-set parameters of the encounter are such that the expectations of such a foreignlocal interaction may actually prejudice and propel the outcome of human resource management practices into a black hole of stalemate and rigidity, a peculiar version of the self-fulfilling prophecy.

A few attempts have been made to analyse this condition critically. For example, Testa (1990) suggests that the dominant management culture in the Seychelles is characterized by participative and negotiative styles, especially in relation to planning and motivation techniques, whereas in other management functions, such as decision making and performance analysis, a bureaucratic approach is allegedly preferred. Aminuzzaman (1992) argues that the overall management culture and practice in the Seychelles is guided by the notion of 'accommodation': 'Managers in general are liberal and flexible to their management practices. The inter-personal relationship between sub-ordinate and peer groups, unlike other Western management culture, is far from the strict principles of bureaucracy' (1992: 2 emphasis added). In an application of Hofstede's (1980) famous international study of management styles, Aminuzzaman (1992: 106) concludes that the Seychellois are essentially reactive, risk aversive, shirk responsibility, have an inordinate adherence to long-standing procedures and fail to initiate revision even when the need for such is acknowledged.

\section{The research data}

The pseudo-scientific character of the Hofstede study and of others modelled on its methodology does much to imbue them with an aura of legitimacy which does not however necessarily stand the test of practice and inductively organized research. Hofstede is, however, correct in claiming that the field of inter-cultural encounter 'offers wide perspectives for research and attractive potential for practical application' (Hofstede, 1985: 356). This falls in line with the increasing recognition being offered to cultural variables in the human resource management practices of international industries (e.g. Wilmott, 1993; Jones et al., 1994).

For this reason, an anonymous and semi-structured questionnaire was prepared and administered to a variety of respondents during May 1996, when the author served as Visiting Lecturer at the Seychelles Institute of Management (SIM). The main 


\section{Godfrey Baldacchino}

respondents were the nineteen participants following the first ever locally offered postgraduate diploma in human resource studies, many of whom occupy senior management positions in the Seychelles public and parastatal sectors. Other respondents included SIM lecturing staff, other personnel officers and high-level officials from the ministries responsible for education. A number of these, as well as other informants, were themselves expatriates. The purpose of the questionnaire was to explore the extent to, and manner in, which the small and island state syndrome discernible in other settings obtained in this Indian Ocean Republic; what its management characteristics were and how these blended (or jarred) with foreign, particularly expatriate, management precepts. Twenty completed and returned questionnaires, along with personal observations and field notes taken during various causal encounters with Seychellois and foreigners, constitute the basis for this exploratory paper.

\section{Response analysis}

There is ready admission by all the respondents of the constraints which the limited domestic manpower base imposes on the Seychellois economy. These include issues already identified above: lack of skilled manpower, especially at personnel management and technical level; continued reliance on the importation of (costly) foreign labour; the brain/skill drain; lack of other (financial, physical) resources to enable human resource development. But other features are also identified. These include the restricted scope for career development and limited opportunities for promotion; the non-competitive labour market leading to individuals claiming uncontested monopoly stature and expertise; the difficulty of releasing such indispensable staff, even to proceed on training; and the increased likelihood of finding workers propelled into senior positions without the commensurate clout to plan and operate proactively:

Very little motivation exists for our people to satisfy ambitions; others very quickly reach the summit and cannot go beyond.

The responses become more vivid and laced with slices of personal experiences when the respondents are probed on features of work-place behaviour which are allegedly associated with the small-scale milieu. Identified elements include collusion, recruitment discrimination, information access, information clamp down and pseudoexpertise. Respondent comments and a critical discussion on each of these follows below.

The increased propensity of finding employees who are related to each other working together. The condition may be avoided but collusive tendencies may result even between employees who are either unrelated or else who are related yet work in different locations. This kind of socially ascribed bondage can lead to the erosion of efficiency, discipline and control; and it is perennially liable to favouritism, selfprotection and nepotism. On the other hand, the situation may be amenable to stronger control and motivation. In any case, accusations of discrimination are likely to circulate even when rewards are assigned fairly and justly:

One managing director had a close friend who eventually married his wife's sister. The friend was then promoted to operations manager. He had very little education.

Personalized recruitment and selection procedures. Elements of discrimination may also be glimpsed in the way that people perceive the identification of personnel in recruitment and promotion situations. There is widespread talk about how 'the 
candidate has been selected beforehand', resulting in a merely formal, procedural charade to bless the predetermined choice. But, in the absence of critical mass, as well as in accordance with the principles of human resource development, it definitely makes sense to identify persons first and to contour and customize a job description afterwards to suit. Once again, hand-picking procedures may be perceived to be liable to foul play:

After having sent in an application for a senior post, I heard through 'radio bamboo' [the local grapevine] that a certain person was earmarked for the job. I phoned the principal secretary and I was told that there are no marks to be seen on anybody's ears. I proceeded with my application, but the earmarked person still got the job. . Everyone knew that the job was his. He was a close friend of the minister.

There may be too many relational, social, political and friendship pressures which are brought to bear:

Some high posts are occupied by certain people because of their political background.

There is the possibility of recruiting the wrong person for the job, or promoting the wrong person. This foments frustration within the organization. The result is poor productivity, demotivation and conflicts among employees.

Hence a worker may be considered [favourably or otherwise] on the basis of connections rather than skills.

Apart from exercising a dampening effect on output and job satisfaction, these pressures can cause reticence, 'group think' (after Janis, 1972) and organizational inertia, out of fear of meeting the disapproval of power-wielding superiors. Such may get translated into the absence of personalized, positive discrimination or a withdrawal from such 'a state of grace'.

The low threshold of privacy in the small and island state scenario ensures that there is fairly widespread and easily available information on any individual's family, social and political background to locate him/her in a matrix of sympathy and antipathy, of potential benefactors and beneficiaries. Radio bamboo does its part to disseminate, free of charge, detailed but also partial and distorted information about what is purportedly going on. As a result, local workers may know - or think they know - too much about each other's (and their managers') personal lives. This may lead to potential blackmail. The situation is one of fabrication of false impressions, of judgement resulting from pre-set notions of employee capability:

[Workers] get into petty arguments...they would spread rumours and gossip to destabilize others, sowing discord and discontent. In a small country, this is bound to happen.

Precisely because this is bound to happen, individuals may react by clamping down on the free transmission of personal data, keeping select information to themselves. Hence a possible cultivation of informal contacts of clients and suppliers, which remains noninstitutionalized and therefore is essentially carried along and maintained by the person. Thus, if that person gets to leave the organization, his/her contacts are carried along with the person and are lost to the institution:

Management could be deprived of informal channels of information and [this would] affect information flow. 


\section{Godfrey Baldacchino}

Finally, workers may consider themselves to be experts when they are actually nothing more than dilettantes by international standards. The 'big fish, small pond' situation can exist because there are few around willing and able to eschew such pseudo-expertise. With limited horizons, there is hardly any fair comparative benchmark for gauging competencies:

There is no skilled person around to contradict 'the expert'.

The condition also results when, in situations of low labour turnover and tight labour markets, you have people occupying posts for many years on end. The tendency is for these people to claim that they know it all, even if their career development has been stunted for the whole period. Indeed, pseuds may even actively avoid training opportunities:

Workers who consider themselves as experts might be repulsive to training. ... Such workers will not accept criticism.

Failure to acknowledge limitations [is a] mentality [which] poses barriers to continuous learning.

\section{Discussion}

The Seychellois way of doing things is seen to contain strong elements of person specificity - in terms of skills, expertise, information, recognition of competence, potentially powerful connections and relations of kin and obligation - all of which militate against institution building. These practices and their internal inter-linkages suggest an informal and tenuous cultural behavioural kit which idiosyncratically colours how workers can act and react to authority. It must be emphasized here that such peculiar (and 'improper') practices do not necessarily happen, or do not happen as often. But if they are expected to happen, people will nevertheless plan suitable preemptive or counter-strategies; they will therefore prove real in their consequences.

What is the managerial response to these local nuances in the Seychelles? Local management is likely to go for 'accommodation' strategies, even because top and middle management are also crafted by the same cultural variables and therefore they carry the same 'good sense' of how to exploit, or of how not to be thwarted by, the small island condition.

Yet, the realization, implicit or otherwise, that these practices suffer from institutional disengagement and lend themselves to dangerous discretionary powers must not be ruled out:

I am the personnel manager here and my daughter is one of the employees. This can be a very dangerous situation.

Therefore, even among the indigenous management cadre, the resort to the diametrically opposite management style - that is, bureaucratic procedurality - can also be conceived as a cautionary safeguard against the possible accusation of partiality, if not as an 'official' justification to an otherwise highly person-specific arrangement.

The resort is even more strongly encouraged and practised by senior, expatriate management. 'Expats' are more liable to feel that they are often alone and up against an indigenous configuration of power which they cannot (and should not?) readily plug into:

It hits you right in the stomach. You recognize early on that you need to fine tune your approach to resonate with the local culture. 
Here, the strategy may also be an intention to hack down the local behavioural syndrome and oblige a return to legal-rational normality, since such also ensures that employee behaviour and human resource management matters are more strongly under institutional (read expatriate top management) control.

One manifestation of this 'foreign management style' is the resort to the written medium. The written word - in the guise of mission statements, internal memos and official performance appraisal forms - becomes a power tool (after Kanter, 1983: 159) which serves to establish a preference for a certain medium of communication. This, of its very nature, stacks power and discretion more readily on the expatriate manager's side. In contrast, the local trait is more liable to feel at home in the safer, less compromising, aural-oral universe of exchange. Difficult issues are circumvented; formal communication is meek and sporadic; relationships override goals and output; there is a lack of forward and succession planning. Situation and person specificity reign supreme.

The capacity of workers to carve out idiosyncratic niches for themselves in otherwise rationalized organizational systems has been referred to as 'skunk works': '[Workers] were creating almost radical decentralization and autonomy with its attendant overlap, messiness around the edges, lack of co-ordination, internal competition and somewhat chaotic conditions' (Peters and Waterman, 1982: 201). This reflects a sense of entrepreneurship, peskiness and resourcefulness which, from the standpoint of the organizational bureaucratic paradigm, is likely to be interpreted dismissively as anarchistic, centrifugal and 'ad-hoc'-istic. Such a judgement is forthcoming from a management cadre frustrated and disempowered by these practices.

\section{When Dionysius meets Apollo}

What possible, generalized outcomes follow from such a value tug-of-war between the local (achieved) and the foreign (ascribed) human resource management styles? What lessons for inter-cultural human resource management?

If the local variant has its way, top (even expatriate) management may find itself engulfed in the social and political matrix of subordinates. This is bound to become a cul-de-sac for managerial discretion. In this way, managers are bound to find their authority eroded once they 'go native' (see, for example, Cullen, 1981: 22). Local employees may come to know this and do their part to take the manager down this dangerous road. Especially for the non-expatriate manager, this may prove to be a road of no return.

In contrast, the foreign may have its way, and the principles of administrative logic may percolate down and through the levels of the organizational hierarchy. Expatriates also typically perceive themselves more as observers than participants in the small island framework in which they may be sojourning for a specific temporary spell. Hence, they can afford to resort to 'cultural toughness' to manage the stress of cultural difference (Mendenhall and Oddou, 1985). Control may be imposed and maintained, via the slavish pursuit of faceless, impersonal blindness to the constraints and opportunities of the small island context. Yet, such a paradigm paralysis can only translate into cultural aloofness and non-sensibility. Furthermore, employees may go through the administrative routines perfunctorily, for their own sake, realizing unconsciously that they represent a certain style of management (read control) which is alien and not attuned to their local environment. The similar, slavish, pursuit of procedures can prove terribly efficient but not necessarily effective. It may result in, for 
example, a plastic and mechanical hospitality service in the tourism industry, so critical for many of these small island settings.

\section{Conclusion}

The Seychelles continues to survive as a rentier, mainly tourism economy, prospering from the very same factors which led to the archipelago's bad fortunes and low incomes in the previous years - namely isolation, small size and few exploitable natural resources (Kaplinsky, 1983: 209-10).

The tourism industry remains the linchpin of the Seychellois economy. Having come late to tourism - the international airport was only built in 1971 - the country appears to have learnt from the mistakes of other tropical holiday destinations by marketing an image of paradise which is sharply focused on exclusive 'tourism products' - birds, coco-de-mer, giant tortoises, marine national parks, coral atolls and two World Heritage sites (Carpin, 1996: 11).

Perhaps, the recognition of this local indigenous natural resource should also extend to an equally local, indigenous management style. The home-grown behavioural equipment and the mesh (or is it a dissonance?) of cultures which invariably results from the encounter call out loud for recognition on their own terms. Rather than going for hard and fast national cultural traits (after Hofstede), there may be ample scope for identifying comparable tendencies on the grounds of the experience of the common ecology of smallness and insularity. The relevance of these traits and the resulting value collision in other 'social island' settings beyond the micro-state milieu should also be seriously considered. Eventually, these human resource management practices may obtain what they deserve: a formal critical evaluation and an assimilation into policy formulation and implementation reviews.

Godfrey Baldacchino

Workers' Participation Development Centre

University of Malta

\section{Acknowledgements}

Many thanks to the Ministry of Administration and Manpower, Republic of the Seychelles, for inviting me as a Visiting Lecturer in May 1996. My appreciation goes to the Seychelles Institute of Management (SIM) for hosting me, to the University of Malta for study leave and to the Commonwealth Secretariat for sponsoring the human resource studies advanced diploma in which I delivered my input. A special note of indebtedness to Marina Confait, SIM Course Director, for providing data and documents and fixing interview schedules. Thanks also to Dennis P. Nickson at the Scottish Hotel School, University of Strathclyde, for constructive criticism on an earlier draft.

\section{Note}

11995 official data identifies 1,545 gainfully occupied permits issued for long-term contracts, of which 688 are for professional and 205 for managerial staff (Source: Immigration Division, Republic of Seychelles). 


\section{References}

Aminuzzaman, S.M. (1992) Public Administration in Micro States. A Case Study of Seychelles. Ethiopia: African Association for Public Administration and Management.

Baker, R. (ed.) (1992) Public Administration in Small and Island States. West Hertford, CT: Kumarian Press.

Baldacchino, G. (1994) 'Peculiar Human Resource Management Strategies? A Case Study of a Microstate Hotel', Tourism Management, 15: 46-52.

Baldacchino, G. (1996) 'Labour Recruitment Practices in Small and Island States: A Different Lesson in Sustainability'. In Briguglio, L., Archer, B., Jafari, J. and Wall, G. (eds) Sustainable Tourism in Islands and Small States: Issues and Policies Vol 1. London: Pinter.

Baldacchino, G. (1997) Global Tourism and Informal Labour Relations: The Small Scale Syndrome at Work. London: Mansell.

Bayliss-Smith, T., Bedford, R., Brookfield, H. and Latham, M. (1988) Islands, Islanders and the World: The Colonial and Post-Colonial Experience in Eastern Fiji. Cambridge: Cambridge University Press.

Bray, M. and Fergus, H.E. (1986) 'The Implications of Size for Educational Development in Small Countries: Montserrat, a Caribbean Case Study', Compare, 16: 91-102.

Bray, M. and Packer, S. (1993) Education in Small States: Concepts, Challenges and Strategies. New York: Pergamon.

Briguglio, L., Archer, B., Jafari, J. and Wall, G. (eds) (1996a) Sustainable Tourism in Islands and Small States: Issues and Policies Vol 1. London: Pinter.

Briguglio, L. Butler, R., Harrison, D. and Leal Filho, W. (eds) (1996b) Sustainable Tourism in Islands and Small States: Case Studies Vol 2. London: Pinter.

Burawoy, M. (1985) The Politics of Production. London: Verso.

Cammish, N.K. (1980) 'Bilimbris et Colibris: A French Curricular Development Project in the Seychelles'. In Brock, C. and Ryba, R. (eds) A Volume of Essays for Elizabeth Halsall. Aspects of Education, No. 22, Hull: University of Hull, Institute of Education.

Carpin, S. (1996) Odyssey Illustrated Guide to Seychelles. Hong Kong: Guidebook Co.

Commonwealth Secretariat (1986) 'Educational Development: The Small States of the Commonwealth', report of pan-commonwealth experts meeting, Mauritius, 1985, London: Commonwealth Secretariat.

Cullen, T.P. (1981) 'Global Gamesmanship: How the Expatriate Manager Copes with Cultural Differences', Cornell Hotel \& Restaurant Administration Quarterly, 22: 18-24.

Dennis, N., Henriques, F. and Slaughter, C. (1956) Coal is Our Life. London: Tavistock.

Dommen, E.C. and Hein, P. (eds) (1985) States, Microstates \& Islands. London: Croom Helm.

Farrugia, C.J. (1991) 'Malta: Educational Development in a Small Island State', Prospects, 21: 584-94.

Ferner, A. and Edwards, P. (1995) 'Organisational Change within Multinational Enterprises', European Journal of Industrial Relations, 1: 561-71.

Firth, R. (1936) We, the Tikopia: A Sociological Study of Kinship in Primitive Polynesia. London: Unwin.

Foucault, M. (1977) Discipline and Punish. Harmondsworth: Penguin.

Gabbay, R. and Ghosh, R.N. (1992) Economic Development in a Small Island Economy: A Study of the Seychelles Marketing Board. Singapore: Academic Press International.

Goffman, E. (1961) Asylums. Garden City, NY: Basic Books.

Handy, C. (1991) The Gods of Management. London: Banner Books.

Handy, C. (1993) Understanding Organisations, 4th edn. Harmondsworth: Penguin.

Harrigan, N.E. (1974) 'The Legacy of Caribbean History and Tourism', Annals of Tourism Research, 2: 13-25.

Harrod, J. (1988) Power, Production and the Unprotected Worker. New York: Columbia University Press. 
Hofstede, G. (1980) Culture's Consequences: International Differences in Work Related Values. London: Sage.

Hofstede, G. (1988) 'The interaction between National and Organizational Value Systems'. Journal of Management Studies, 22: 347-357.

Janis, I.L. (1972) Group Think: Psychological Studies of Policy Decisions and Fiascos. Boston, MA: Houghton Mifflin.

Jones, C., Nickson, D. and Taylor, G. (1994) 'Ways of the World: Managing Culture in International Hotel Chains'. In Seaton, A.V. (ed.) Tourism: The State of the Art. Chichester: Wiley.

Kanter, R.M. (1983) The Change Masters: Corporate Entrepreneurs at Work. London: Unwin.

Kaplinsky, R. (1984) 'Prospering on the Periphery: A Special Case - The Seychelles'. In Cohen, R. (ed.) African Islands and Enclaves. London: Sage.

Khan, J. (1976) Development Administration: Field Research in Barbados. Bridgetown, Barbados: Yoruba Press.

Kotas, R. (1980) Managerial Economics for Hotel Operations. Guildford: University of Surrey Press.

Laclau, E. (1990) Reflections on the Revolution of Our Time. London: Verso.

Lockhart, D. and Drakakis-Smith, D. (eds) (1996) Island Tourism: Problems and Prospects. London: Mansell.

McKee, D.L. and Tisdell, C.A. (1990) Developmental Issues in Small Island Economies, New York: Praeger.

Malinowski, B. (1922) Argonauts of the Western Pacific. London: Routledge.

Mead, M. (1949) Coming of Age in Samoa. London: Penguin.

Mendenhall, M. and Oddou, D. (1985) 'The Dimension of Expatriate Acculturation: A Review', Academy of Management Review, 10: 39-47.

Olsen, M.D., Crawford-Welch, S. and Tse, E. (1991) 'The Global Hospitality Industry of the 1990s' in Teare, R. and Boer, A. (eds) Strategic Hospitality Managment: Theory and Practice for the 1990s. London: Cassell.

Peters, T. and Waterman, R.H. (1982) In Search of Excellence: Lessons from America's Best Run Companies, New York: Harper \& Row.

Pillay, P. and Murugiah, A. (1991) 'Seychelles'. In Bray, M. (ed.) Ministries of Education in Small States: Case Studies of Organisation and Management. London: Commonwealth Secretariat.

Pitt, D. (1980) 'Sociology, Islands and Boundaries', World Development, 8: 1051-9.

Republic of Seychelles (1995) Statistical Abstract 1994. Mahé: Management and Information Systems Division.

Republic of Seychelles (1996) Human Resource Development Programme 1994-2000: Progress Report. Mahé: Manpower Division, Ministry of Administration and Management.

Rushen, S.F. (1995) 'Fluctuations and Downturns in a Company Town', Growth and Change, 26: 611-16.

Shamir, B. (1981) 'The Workplace as a Community: The Case of British Hotels', Industrial Relations Journal, 12: 45-56.

Sztompka, P. (1990) 'Conceptual Frameworks in Comparative Inquiry: Divergent or Convergent? In Albrow, M. and King, E. (eds) Globalization, Knowledge and Society. London: Sage.

Testa, S. (1990) 'Dominant Management Culture in the Seychelles', unpublished report, Mahé. Tunstall, J. (1969) The Fishermen. London: Routledge \& Kegan Paul.

Villamil, J.J. (1977) 'Size and Survival: Planning in Small Island Systems', Microstate Studies, 1: $1-7$.

Wilmott, H. (1993) 'Strength is Ignorance; Slavery is Freedom: Managing Culture in Modern Organisations', Journal of Management Studies, 30: 515-52.

Woods, R.H. (1992) Managing Hospitality Human Resources, East Lansing WI: Educational Institute of the American Hotel \& Motel Association. 